\title{
INÉDITOS E DISPERSOS: NOTAS SOBRE AUTONOMIA POÉTICA EM ANA CRISTINA CESAR SOB A ÓTICA DE PIERRE BOURDIEU
}

\author{
Alessandra Zelinda Sousa Bessa \\ Mestre em Literatura Comparada pela Universidade Federal do Ceará (UFC) \\ lekabessa_87@hotmail.com
}

\section{RESUMO}

Este estudo tem como objetivo fazer um debate acerca da autonomia literária em Inédito e Dispersos (1985) de Ana Cristina Cesar sob o prisma de Pierre Bourdieu. Nessa perspectiva faremos uma reflexão sobre a teoria de campos em Les regles de l'art (1996). Analisaremos a estética da poesia de Cesar em debate com a autonomia literária. Entendemos os aspectos do simbólico, do registro do acaso, da fragmentação do pensamento e do uso excessivo de figuras de linguagem corroboram as concepções de Bourdieu, já que mostram, no espaço de campos políticos, a ruptura hegemônica da forma. Concluímos que a literatura de Cesar aparece como manifestação artística independente a partir do espaço interpretativo dos leitores, revelando os campos de poderes, amplitude do imaginário e do inconsciente simbólico. Adorno (2003), Agamben (2008), Barthes (2010) e Rancière (2009), dentre outros, são alguns dos autores que representam nosso aporte teórico.

Palavras-chave: Autonomia poética; Literatura; Ana Cristina Cesar; Pierre Bourdieu.

\begin{abstract}
This study aims to make a debate about the literary autonomy in Inéditos e Dispersos (1985), by Ana Cristina Cesar, under the reading of Bourdieu. From this perspective, we reflect about the field theory from Les regles de l'art (1996). We analyze the aesthetics of Cesar's poetry in debate with literary autonomy. We understand the aspects of the symbolic, the register of chance, the fragmentation of thought and the excessive use of figures of language corroborate the conceptions of Bourdieu, since they show, in the space of political fields, the hegemonic rupture of the form. We conclude that the literature of Cesar appears as an independent artistic manifestation from the interpretive space of the readers, revealing the fields of powers, amplitude of the imaginary and the symbolic unconscious. Adorno (2003), Agamben (2008), Barthes (2010) and Rancière (2009), among other scholars, are some of the authors that represent our theoretical contribution.
\end{abstract}

Key-words: Poetic Autonomy, Literature, Ana Cristina Cesar, Pierre Bourdieu. 
Ana Cristina Cruz Cesar (1952-1983) foi uma poeta carioca, graduada em Letras pela PUC-Rio e mestre em Comunicação. Em seu curto período de vida, conseguiu destaque significativo na literatura brasileira como poeta, ensaísta, crítica literária e tradutora. Traduziu os contos de Katherine Mansfield, Emily Dickinson e Sylvia Plath e possui as seguintes obras publicadas: Cenas de Abril (1979), Correspondência completa (1979), Luvas de Pelica (1980), A teus pés (1982) e Literatura não é documento (1980), Inéditos e dispersos (1985), Crítica e Tradução (1999), Novas Seletas, Poética: obra completa (2015), Correspondência Incompleta (1999), Escritos no Rio (1993), Escritos em Londres (1993), Ana Cristina Cesar: o sangue de uma poeta (1996).

A coletânea 26 poetas hoje (1976), organizada pela professora Heloísa Buarque de Hollanda, reuniu poesias marginais dos anos 70, que possuem as seguintes características: fruição da linguagem, fragmentação poética, ênfase no cotidiano, paródias, comicidade, palavrões e uso do duplo sentido. Porém, como afirmou Hollanda (1999), Ana Cristina é considerada "uma poeta marginal especial". Mesmo frequentando os encontros do grupo da poesia marginal, possuía uma performance poética mais acurada e específica em relação aos demais poetas. De acordo com Nascimento (2015) e Britto (2016), Ana Cristina Cesar desenvolveu uma maneira diferente de escrever poesia, apresentando estrutura refinada de criação simbólica e de aprofundamento da polissemia do texto.

Os textos poéticos de Cesar aparecem numa dupla independência artística, que evidenciam autonomia tanto na maneira de divulgação (publicadas artesanalmente) como na maneira de criação estética dos textos (desvinculavam dos padrões estabelecidos da época). No que se refere à autonomia estética, depreendemos "a ambiguidade léxicosintática, a suspensão do sentido, as incongruências, a aproximação caótica de elementos aparentemente desconexos, o resgate intertextual" (SALVINO, 2002, p. 71). 
Esses aspectos trazem uma visão dual da realidade e resultam em reflexões questionadoras da forma padrão de criar. Conforme Agamben (2007, p. 48), “os dizeres são processos sem vozes específicas, tornam-se lugares sem autoria". Observamos a tensão e instabilidade a partir das caracterizações fragmentárias, fluidas e plurissignificativas de sua poesia, que acabam por sinalizar a ruptura da hegemônica maneira de pensar, de falar ou mesmo de viver.

Podemos dizer que os jogos de figuras de linguagem são um dos traços da dicção dos poemas de Cesar, que desenvolvem um minucioso trabalho com a linguagem e viabilizam uma amplitude de percepção do mesmo ponto lido. É através dos sentidos que os leitores são levados a compreender e interiorizarem os versos da poeta. Confrontando o padrão político da forma, exercido pela burguesia dominante, que insere um valor "purista da autonomia da arte, num entendimento determinista ou instrumental do objecto artístico" (CACHOPO, 2017, p. 45) e trazem "no encapsulamento da crítica de arte a ideia de juízo irredutível" (CACHOPO, 2017, p. 45). Por conseguinte, observamos que a autonomia das poesias de Cesar contradizem o "imediatismo dos resultados efêmeros e passageiros" (GALVÃO, 1985, p. 150).

Em Inédito e dispersos (1985), a fragmentação das palavras, a hesitação do dizer, os jogos intertextuais e as marcas linguísticas de figura de linguagem criam enigmas das quais seduzem os leitores. No entanto o eu lírico parece se "esquivar", através de imagens e símbolos complexos, a serem decifrados, mesmo comunicando algo do cotidiano. Assim, a descrição dos seus pensamentos, de estereótipos, de impressões e de sensações íntimas do eu lírico são vinculados aos códigos poéticos, sendo apenas um ponto de partida para reflexões mais complexas. 
Assim sendo, a poesia de Ana Cristina, ao trazer o mistério, a sedução e o enigma vai "tecendo uma estrutura complexa e cambiante em que os limites entre o que lhe é próprio e o que é dos outros (escritores, leitores) desaparecem a cada momento" (SALVINO, 2002, p. 66).

O presente artigo pretende refinar a leitura acerca da autonomia literária, vigente em Ana Cristina Cesar, buscando o debate com alguns teóricos da estética literária sobre recepção do texto, campo literário e seus desdobramentos, com enfoque em As regras da arte (1996), de Pierre Bourdieu.

Antes de tudo, necessitamos de algumas notas acerca da teoria dos campos trazida pelo sociólogo francês. Segundo o estudioso, os sujeitos são formados pela repetição de comportamentos absorvidos pelas estruturas sociais, chamada de habitus. Os indivíduos interiorizam estas estruturas de maneira inconsciente e formam suas percepções de mundo através do enraizamento cultural. A questão da teoria dos campos entra como espaço de lutas, a partir das relações com vários tipos de campos: o econômico, o literário, o simbólico, o político, dentre outros, dos quais se mostram como forças conflitantes.

Essas instabilidades de conceitualizações e interpretações do objeto literário trazem à tona o real que está submerso no inconsciente dos leitores, pois "a forma na qual se enuncia a objetivação literária é sem dúvida o que permite a emergência do real mais profundo [...]" (BOURDIEU, 2002, p. 42). O que nos leva a compreender o conceito de capital cultural como "carga cultural que recebemos - principalmente na primeira socialização - e que permanece ao longo de nossa vida, dizendo de nossos gostos, posturas, de nossa relação e familiaridade (ou não) com certas práticas culturais" (PEREIRA, 2015, p. 345). De acordo com Bourdieu (2002, p. 44), o estranhamento é motivado pela linguagem artística que é fator resultante do conflito entre a essência pura do real e o olhar social 
arbitrário do real, dizendo com as palavras do autor "a relação de dupla recusa das posições".

Entendendo, então, que no seio da literatura existem diferentes forças, as quais defendem seu território social, político e cultural. Todavia, compartilham de uma única necessidade: a emancipação do eu a partir do objeto literário. Trazendo Rancière (2009) para o debate, entendemos a literatura como objeto radicalizador do real, observada dentro da "partilha do sensível", ou seja, ela evidencia o lado universal dos homens a partir da arte. Logo, para o estudioso a literatura é a própria expressão da essência dos sujeitos. Em outras palavras, é uma entidade que permite o receptor formar seu próprio discurso a partir da linguagem inerente ao espaço artístico.

Acerca disso, entendemos que a dimensão da comunicação, seja ela através da escrita, da fala ou da imagem, é sempre entremeada de outros discursos. Sob esse aspecto, Abdala Junior (2014, p. 36) diz que a escrita, "em razão da dialética de nosso processo histórico, pode vir a espartilhar os horizontes de seu próprio campo, pois que o conhecimento está sempre em interações/friç̧ões, motivado, sobretudo pelas relações interdisciplinares com as outras áreas do conhecimento" que se abre para novas e criativas conformações. Onde o escritor acaba por tornar o texto um novo lugar de percepções de ideias e "abre-se a possibilidade real de se estabelecer efetivos contrapontos" (JUNIOR, 2014, p. 38).

Dessa maneira, as vozes, encontradas nos textos, são lidas, reescritas e repartidas de modo diferenciado. Roland Barthes (2010) pontua que os discursos literários possuem fluidez e se espalham "como água" na proporção em que firmam seus territórios. Confirmando que o substrato da poesia de Cesar é calcada no domínio de espaços. Essa fluidez de entendimento da arte se mostra na própria natureza diversa dos campos instituídos. 
"É nesse sentido que falará de um "mistério" inerente à obra de arte" (GAGLIARDI, 2000, p. 59) - em que autonomia, campo literário e campo de poder seguem juntos. Mas, por sua vez, se voltam a um percurso "errante" que não singulariza o dizer, pois afirmam a "diluição de fronteiras [...]" (GAGLIARDI, 2000, p. 108). Nesse sentido, o fenômeno da poesia é apresentado como estética, desenvolvendo a capacidade de criar experiências singulares entre o receptor e a obra.

Deleuze diz que "a escrita é inseparável do devir; ao escrever, estamos num devirmulher, num devir-animal ou vegetal, num devir-molécula, até num devir imperceptível" (DELEUZE, 1997, p. 11). No entanto Bourdieu (1989) percebe a escrita como "violência simbólica", ou melhor dizendo, como estruturas mentais criadas para defender seu espaço de sobrevivência. Consequentemente, os campos de produção possuem um capital cultural, um habitus que permite a apreciação e compreensão das obras segundo determinada perspectiva. Já que "o habitus, como indica a palavra, é um conhecimento adquirido e também um haver, um capital" (BOURDIEU, 1989, p. 61).

Como foi mencionado, anteriormente, as poesias de Ana Cristina Cesar tentam romper com o estilo convencional de perceber o mundo, mas sem um engajamento direto. Para tanto observamos que a plenitude da arte de Cesar "é radical no não radicalismo, ao se abster a qualquer redução a um princípio e ao acentuar em seu caráter fragmentário o parcial diante do total" (ADORNO, 2008, p. 17).

Nesse interim, para o entendimento da sua poética, é necessário um tipo específico de habitus, um capital cultural. Outrossim, são espaços que desenvolvem os inconscientes imagéticos dos seres humanos e compreende tudo aquilo que o rodeia. Adiante tentaremos demostrar esse fato em A terceira margem: 


\author{
Era uma terceira noite \\ O giroscópio girava girando \\ Minha gravata balouçava no ar \\ Meus guizos tocavam tocando \\ Meu coração batia batendo \\ [...] (CESAR, 2013, p. 138).
}

Observamos que as expressões, "terceira noite", "giroscópio girava girando" e "guizos tocavam tocando" buscam um tipo sinestésico de entendimento do texto e acabam por suscitarem situações específicas de interpretação a partir dos sentidos. Corroborando a ideia de que os "poemas são tão silenciosos como as estátuas. A poesia é um uso desinteressado da palavra: não se volta para qualquer leitor diretamente" (FRYE, 1973, p.13). Continuando no mesmo poema:

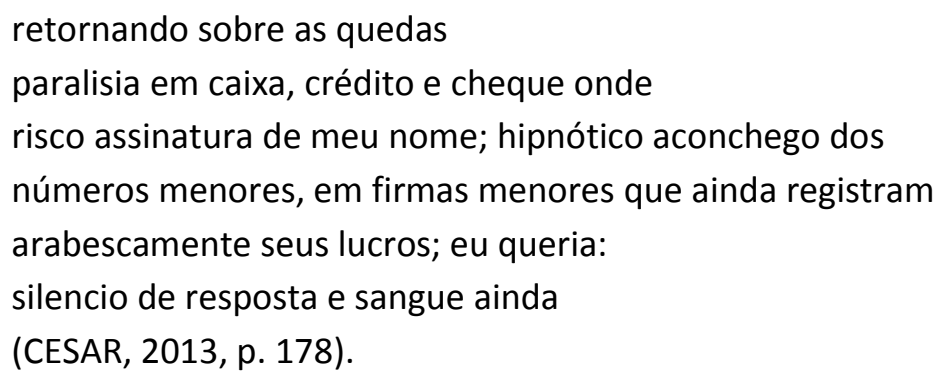

Também presenciamos um texto de complexa trama simbólica, da qual a semântica desenvolve essa complexidade. Tomemos a primeira expressão para análise "retornando sobre as quedas/paralisia em caixa, crédito e cheque onde/risco assinatura de meu nome". A voz do poema insinua, de maneira decepcionada, que um tipo de repartição pública (qualquer representação de banco burocrático) o faz ficar paralisado. Porém, a paralisia se mostra como um símbolo, que pode ser: psicológica, física, emocional e material. Dependendo de como o leitor vai interpretá-lo e conseguintemente acionará seu capital cultural. 
O texto continua: "onde risco assinatura de meu nome; hipnótico aconchego dos números menores". A hipnose nos liga ao mágico ou ao lado psíquico da mente e o poema deixa claro que os números menores possuem esse poder sobre o interlocutor. Podemos desenvolver um raciocínio de que o eu lírico se sente mais à vontade em "firmas menores que ainda registram arabescamente seus lucros", pois sente comodidade com o que já conhece neste ambiente. E, arremata: "eu queria: silêncio de resposta e sangue ainda", onde cria uma atmosfera densa, da qual o próprio eu lírico simboliza seu dizer (representada pelo sangue e pelo silêncio de resposta). Trata-se dos pensamentos e dos anseios que o eu lírico deixa nas entrelinhas do texto. Logo, a poesia desenvolve esse caráter de imprecisão nos leitores. Mais adiante, temos outros versos de Cesar, nos quais a figura do gato aparece:

O gato era um dia imaginado nas palavras

Conforme os gatos diários pensamentos

(...)

O gato era excluso do meu tempo

e arranhava em espaços esse dia

(CESAR, 2013, p. 181).

Ao imaginar a figura do gato e ao remeter ao estereótipo comum, o sujeito do poema não se identifica com a imagem e diz que esse tipo de gato é "excluso do seu tempo". Com isso sente que o felino "arranhava em espaços esse dia", ou seja, não preenchia as lacunas da sua imaginação. Para tanto o gato é pensado "em função de conjunturas históricas diversas daquela para a qual foi criada" (FREITAS, 2005, p. 115). Como podemos perceber nos versos seguintes:

O nome morto vira lápide, 
Falsa impressão de eternidade.

Nem mesmo o cio exterior escapa

À presa discursiva que não sabe

(CESAR, 2013, p. 181).

Consequentemente, as fragmentações trazidas por Cesar se fazem visíveis, pois entendem que o plano dos sentidos das expressões e palavras são fluídicas e vão variar também de acordo com o tempo em que estão imersos. A seguir a poesia intitulada Poesia corrobora essa afirmativa:

\author{
Jardins inacabados pensamentos \\ Pretensas palavras em \\ Pedaços \\ Jardins ausenta-se \\ A lua figura de \\ Uma falta contemplada \\ Jardins anteriores que \\ Recuam \\ Ausência frequentada sem mistério \\ Céu que recua \\ Sem pergunta \\ (CESAR, 2013, p. 208).
}

Os pensamentos são como jardins inacabados ou os pensamentos inacabados são como jardins? Não temos a resposta no texto. Já que o interlocutor é alguém confuso. Essa sensação se reflete na natureza a partir da ausência, do recuo do céu, no mistério e através da lua que insinua a falta de algo. Em Vigília II, a poeta trabalha novamente com traços da natureza:

As paisagens cansei-me das paisagens

Cegá-las com palavras rasurá-las

As paisagens são frutos descabidos 
Agudos olhos farpas sons à noite

Espaço livre para erro regiões recompostas

Por desejo [...]

(CESAR, 2013, p. 207).

Para o eu lírico a natureza é percebida através de construções ilusórias do desejo. Como o próprio poema diz "espaço livre para erro regiões recompostas /por desejo." E, por entender esse fato, o interlocutor sente as paisagens de maneira errante. Por consequência, busca no reino das palavras, outras representações dessas paisagens, como podemos observar nesse trecho: "as paisagens cansei-me das paisagens/cegá-las com palavras rasurá-las". Com isso, essa fragilidade diante do mundo, se mostra como manifestações diversas na poética de Ana Cristina Cesar. O que também é percebido nas poesias de cunho sentimental:

\author{
quando desisto é que surges \\ quando ruges é que caio \\ quando desmaio é que corres \\ quando te moves me acho \\ quando calo me curas \\ e se te misturo me perco \\ (assobia!) \\ (CESAR, 2013, p. 160).
}

O texto não deixa claro o porquê dos atos de desistir versus surgir, rugir versus cair, desmaiar versus correr, mover versus achar, calar versus curar e misturar versus perder. Mas sabemos que existem duas pessoas interagindo através de atos, dos quais sempre se distanciam para se aproximarem. Mostrando que o eu lírico é um ser impotente diante dos reflexos dessa outra pessoa e está totalmente entregue a essa dança. Desenvolvendo, portanto, a violência simbólica mencionada por Pierre Bourdieu (1996), do qual 
se mostra no espaço de lutas veladas, através dos atos de distanciamento do campo do outro e trazendo tensão. O eu lírico simboliza o seu dizer de negação do modo de vida estabelecido pela sociedade. Logo, "o comportamento exótico são vividos e sentidos como gestos perigosos" (CESAR, 1999, p. 217).

Dessa maneira a poética de Ana é caracterizada pela "materialidade do fenômeno artístico dentro do seu relativismo existencial" (CÂMARA, 2013, p. 102) e se faz autônoma, na medida em que consegue um lugar aberto a várias interpretações a partir do habitus desenvolvido através do leitor.

Por fim, o uso de termos simbólicos, de ambiguidades, de excentricidades, do olhar cético diante da vida e a transgressão da ideia fixa da forma são alguns dos fatores que criam as diversas tensões na tessitura poética de Ana Cristina Cesar. Dessa maneira, o livro Inéditos e Dispersos deixa visível o modo de construção estética dos textos de Ana C. como um "mudo convite". Nele, o registro do acaso e dos flashs dos momentos criam a teia simbólica da autonomia do texto.

Assim, conclui-se, a partir de Bourdieu, que a autonomia na obra Inédito e Dispersos se faz através: 1) da ruptura com os campos e habitus hegemônicos visualizado através da estética do texto; 2) da fragmentação do dizer, da dispersão do pensamento, da espontaneidade da linguagem, dentre outros aspectos; 3) da particularização da linguagem e da desautomatização do padrão da forma; 4) da tensão trazida pela plurissignificatividade do símbolo a partir da presença de reflexões entremeada dos diversos territórios políticos.

\section{Referências}


ABDALA JUNIOR, Benjamin. Estudos literários e crítica política. Revista Conexão Letras. Porto Alegre, UFRGS, n. 14, p.124-135, 2014.

ADORNO, T. W. Ensaio como forma. In: Notas de Literatura I. Tradução Jorge M. B. de Almeida. São Paulo: Duas Cidades; Ed. 34, 2003. Notas de Literatura I. Tradução Jorge de Almeida. São Paulo: Livraria Duas Cidades; Editora 34, 2003.

AGAMBEN, Giorgio. Arte, Inoperatividade, Política. Trad. Simoneta Neto. In: Política (Críticas do Contemporâneo: Conferências Internacionais Serralves). Serralves: CEM Artes Gráficas; Fundação Serralves, 2008. p. 39-49.

BARTHES, R. O prazer do texto. Tradução J. Guinsburg. 5. ed. São Paulo: Perspectiva, 2010. BOURDIEU, Pierre. As regras da Arte: gênese e estrutura do campo literário. São Paulo: Companhia das Letras, 1996.

O poder simbólico. Tradução Fernando Tomaz. 11. ed. Rio de Janeiro: Bertrand Brasil, 2007.

BRITTO, Clovis Carvalho. Economia simbólica dos acervos literários: itinerários de Cora Coralina, Hilda Hilst e Ana Cristina César. 2016. 185f. Tese (Doutorado em Sociologia) Universidade de Brasília, Brasília, 2016.

CACHOPO, João Pedro. Entre o singular e o plural: notas sobre arte, autonomia e política. O que nos faz pensar: cadernos do Departamento de Filosofia da PUC-Rio. Rio de Janeiro: Pontifícia Universidade Católica do Rio de Janeiro, n. 1,1989, p. 35-46.

CÂMARA, Sergio. Autonomia da arte: notas de estética. Conhecimento \& Diversidade, Niterói, n. 9, 2013. p. 99-106.

CESAR, Ana Cristina. Inéditos e Dispersos. In: FILHO, Armando Freitas. Ana Cristina Cesar/Poética. São Paulo: Companhia das Letras, 2013. p. 7-503.

DELEUZE, Gilles. Crítica e clínica. Tradução Peter Pálpelbert. São Paulo: Editora 34, 1997.

FREITAS, Mariana Nunes de. Escritas do eu em Ana Cristina César: uma pseudoautobiografia. 2014. 129f. Dissertação (Mestrado em Linguística, Letras e Artes) - Universidade Federal de Uberlândia, Uberlândia, 2014.

FRYE, Northrop. Anatomia da crítica. Tradução Péricles Eugênio da Silva Ramos. São Paulo: Cultrix, 1973.

GAGLIARDI, Caio Márcio Poletti Lui. A construção do cânone crítico sobre Fernando Pessoa: a crítica de Adolfu Casais Monteiro I Caio Márcio Poletti Lui Gaglíardi. Campinas, São Paulo: [s.n.], 2000. 
HOLLANDA, Heloísa Buarque de. Sobre a correspondência. In: CESAR, Ana Cristina. Correspondência completa. Rio de Janeiro: Aeroplano, 1999.

NASCIMENTO, Maria Imaculada Angélica. Por uma janela aberta: pulsão poética e tradução na obra de Ana Cristina Cesar. 2015. 308f. Tese (Doutorado) - Universidade Federal de Minas Gerais, Faculdade de Letras, Belo Horizonte, 2015.

PEREIRA, Elaine Aparecida Teixeira. O conceito de campo de Pierre Bourdieu: possibilidade de análise para pesquisas em história da educação brasileira. Revista Linhas, Florianópolis, v. 16, n. 32, p. 337-356, 2015.

RANCIÈRE, Jacques. A partilha do sensivel: estética e política. Tradução Mônica Costa Netto. São Paulo: Editora 34, 2009.

SALVINO, R. V. Ana Cristina Cesar: entre o eu e o outro. Estudos de Literatura Brasileira Contemporânea, Brasília: UnB, n. 19, 2002, p. 59-82.

SALVINO, Romulo Valle. Ana Cristina Cesar: entre o eu e o outro. Disponível em: $<$ http//www.file://C:/Users/User/Downloads/Dialnet-AnaCristinaCesar6120284\%20(2).pdf>. Acesso em: 02 maio 2019.

PINTO, Maria do Rosário. Catalogação de folhetos de cordel. Rio de Janeiro: Funarte, CNFCP, 2002.

ROULET, E. La description de l'organisation du discours. Du dialogue au texte. Paris: Didier, 1999.

SOLÉ, Isabel, Estratégias de leitura. Tradução Cláudia Schilling. 6. ed. Porto Alegre: Artmed, 2009.

THIOLENT, M. Metodologia da pesquisa-ação. São Paulo: Cortez, 1992.

TODOROV, Tzvetan. A literatura em perigo. Rio de Janeiro: DIFEL, 2009.

Recebido em 22 de maio de 2019.

Aceite em 08 de agosto de 2019. 